\title{
Robotic right medial and anterior basal segmentectomy (S7+S8)
}

\author{
Pierre-Benoit Pagès ${ }^{1,2}$, Leslie Madelaine ${ }^{1,2}$, Ivan Gutierrez ${ }^{1}$ \\ ${ }^{1}$ Department of Thoracic Surgery, CHU Dijon, 14 rue Gaffarel, 21079 Dijon, France; ${ }^{2}$ INSERM UMR 1231, CHU Dijon, University of Burgundy, \\ Dijon, France \\ Contributions: (I) Conception and design: PB Pagès, I Gutierrez; (II) Administrative support: PB Pagès, L Madelaine; (III) Provision of study materials \\ or patients: PB Pagès, L Madelaine; (IV) Collection and assembly of data: PB Pagès, L Madelaine; (V) Data analysis and interpretation: PB Pagès, I \\ Gutierrez; (VI) Manuscript writing: All authors; (VII) Final approval of manuscript: All authors. \\ Correspondence to: Pierre-Benoit Pagès, MD, PhD. Department of Thoracic and Cardiovascular Surgery, CHU Dijon, Hôpital du Bocage, 14 rue \\ Gaffarel, BP 77908, 21079 Dijon, France. Email: pierrebenoit.pages@chu-dijon.fr.
}

\begin{abstract}
The use of anatomical segmentectomy has expanded along with the improved detection of ground-glass opacities and the growing incidence of second primary lung cancer in compromised patients. In our opinion, an approach combining preoperative 3-dimensional reconstruction and the Da Vinci surgical system can be used to perform less invasive anatomical segmentectomies with sufficient surgical margins.
\end{abstract}

Keywords: Segmentectomy; lung cancer; robotic-assisted thoracic surgery; preoperative imaging

Received: 05 March 2020; Accepted: 30 April 2020; Published: 20 July 2021.

doi: $10.21037 /$ jovs-2020-12

View this article at: http://dx.doi.org/10.21037/jovs-2020-12

\section{Introduction}

During the last decade, the detection of small nodules has increased dramatically along with the number of CT scans. At the same time, the quality of preoperative imaging has improved with the introduction of preoperative $3 \mathrm{D}$ planning (1). Anatomical segmentectomy is therefore becoming more common in Western countries. The optimal approach to minimally invasive anatomical segmentectomy includes a combination of 3-dimensional (3D) visualization, robot-assisted thoracic surgery (RATS), which provides an increased degree of motion and rotation freedom, and small-wristed instruments designed to facilitate complex movements $(2,3)$.

\section{Patient selection and workup}

A 75-year-old man with a history of lymphoma presented with ground-glass opacity (GGO) that was detected on a routine chest CT scan (Figure 1). The nodule was hot on PET CT with a standard uptake value (SUV) of 5.4. Preoperative fibroscopy was negative. Forced expiratory volume was $3.73 \mathrm{~L}(116 \%)$ and $\mathrm{KCO}$ was $93 \%$.

Preoperative 3D reconstruction with Visible Patient ${ }^{\mathrm{TM}}$ (Strasbourg, France) was performed according to manufacturer instructions (Figure 2).

\section{Equipment preference cards}

(I) $3 \mathrm{D}$ high-definition camera $\left(30^{\circ}\right.$ lens).

(II) One cadiere forceps to retract tissue during the dissection of vessels and bronchus.

(III) One Maryland forceps connected to an additional $\mathrm{ERBE}^{\odot}$ generator (ERBE, Limonest, France) used for electrocoagulation, sectioning and in order to dissect free the vessels and bronchus.

(IV) One tip-up forceps used to retract lung parenchyma and to better expose the surgical field.

(V) MEDTRONIC $^{\odot}$ Signia Stapler with $30 \mathrm{~mm}$ gold vascular curved reload, 45 and $60 \mathrm{~mm}$ purple curved reloads.

\section{Surgical management}

\section{Positioning}

Under general anesthesia, after selective intubation, the patient was placed in lateral decubitus on axillary rolls, with the right arm on an armrest.

The DaVinci Xi Surgical system (Intuitive surgical SAS, 
Montrouge, France) was placed perpendicular to the table. The patient position was similar to conventional surgery, with the head placed close to the anesthesia station.

\section{Port placement (Figure 3)}

First, an 8-mm port was placed just below the scapular spine in the $6^{\text {th }}$ intercostal space (Arm 3). The airseal port was then

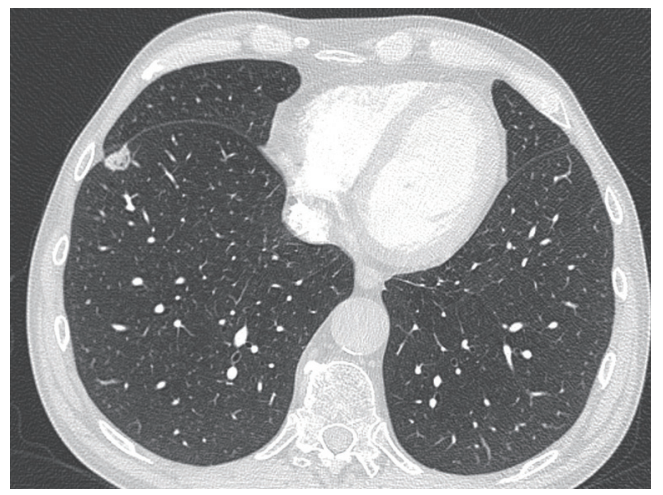

Figure $1 \mathrm{CT}$ scan showing the nodule in the anterior part of the S7-S8 segment. placed in the $9^{\text {th }}$ intercostal space, on the anterior axillary line. Robotic arm port $1(8-\mathrm{mm})$ was placed in the $6^{\text {th }}$ intercostal space on the posterior axillary line, arm port $2(8-\mathrm{mm})$ was placed in the $8^{\text {th }}$ intercostal space on the posterior axillary line, and arm port $4(8-\mathrm{mm})$ port was placed in the $6^{\text {th }}$ intercostal space on the anterior axillary line.

After docking the robot, a $30^{\circ}$ camera was introduced through the Arm 3. A tip-up forcep was inserted in arm port 1, a Cadiere grasper was inserted in arm 2 and a Maryland bipolar forceps was inserted in arm port 4.

The surgical assistant was positioned in front of the patient with a long suction tip.

\section{Surgical technique (Video 1)}

After a mediastinal lymph node dissection (not shown in the video), the right upper and middle lobes were retracted apically with Arm 1, the major fissure was opened, and the main pulmonary artery was dissected free with the bipolar Maryland forceps. The anterior part of the fissure was completed with bipolar forceps after identification of the middle lobe artery.

After identifying A6, the intersegmental lymph
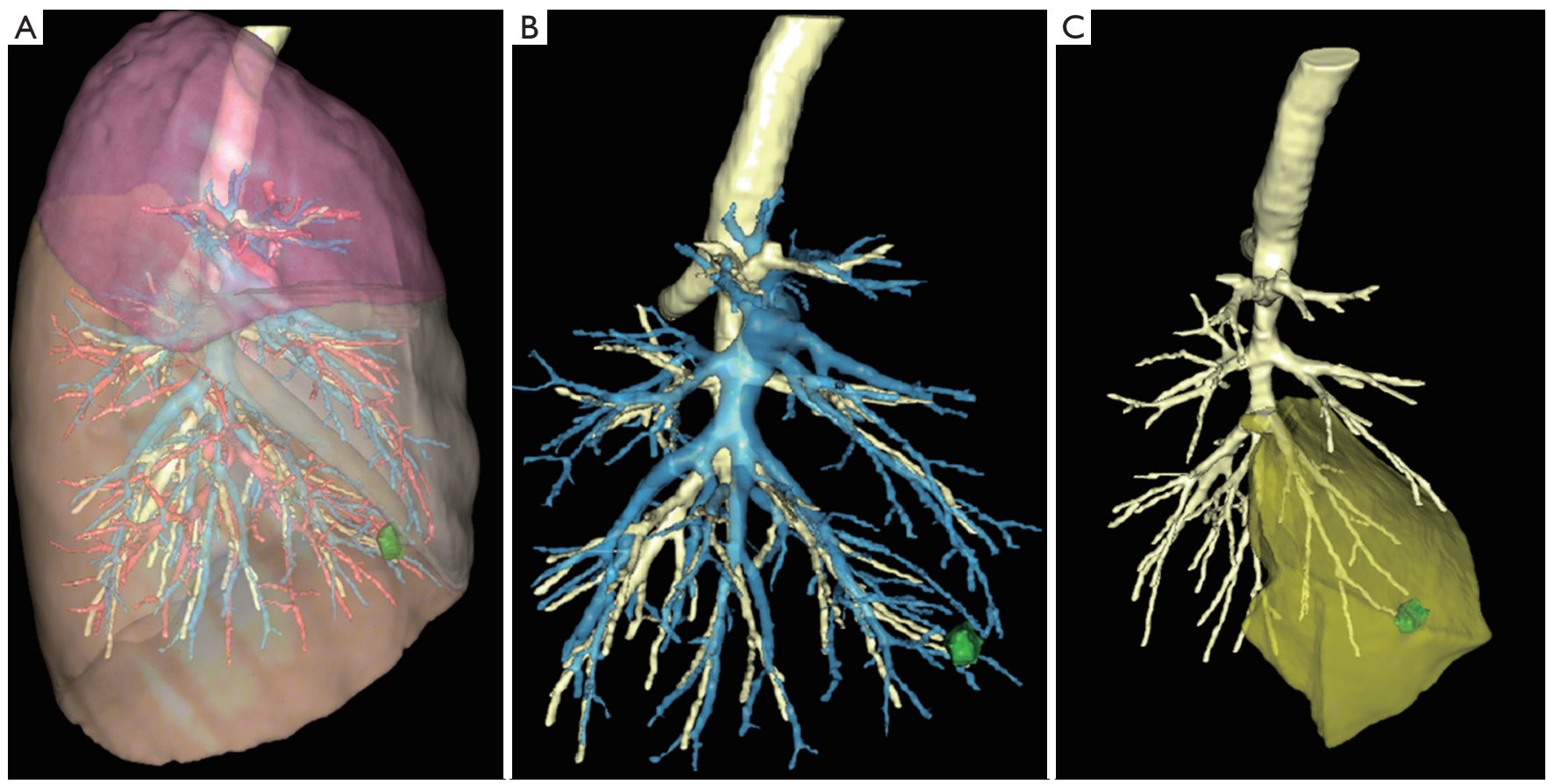

Figure $23 \mathrm{D}$ reconstruction (Visible Patient ${ }^{\mathrm{TM}}$ ) of the right lung. (A) The nodule is marked in green in the whole right lung; (B) anatomical distribution of the branches of the pulmonary artery for the 3 lobes; (C) lung parenchyma volume ventilated by the segmental bronchus B7-B8. 


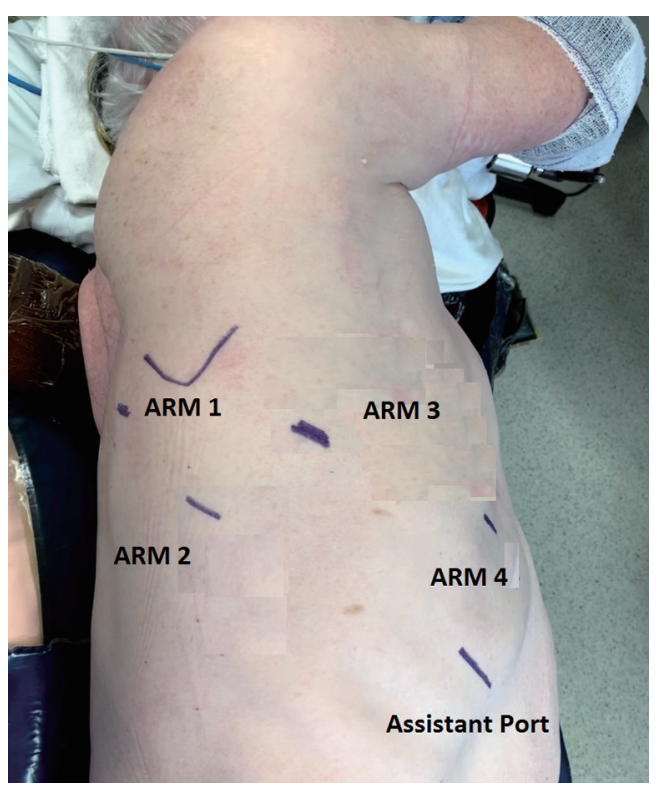

Figure 3 Port placement for right side robot-assisted thoracic surgery.

node (level 12) was dissected free and sent for frozen section. The basal artery was then dissected in order to identify $\mathrm{A} 7+\mathrm{A} 8$ and $\mathrm{A} 9+\mathrm{A} 10$, using the preoperative $3 \mathrm{D}$ reconstruction of the artery. $\mathrm{A} 7+\mathrm{A} 8$ was stapled and transected with a $30 \mathrm{~mm}$ vascular curved stapler. The basilar bronchus was then exposed and we identified $\mathrm{B} 7+\mathrm{B} 8$ and $\mathrm{B} 9+\mathrm{B} 10$ using the preoperative $3 \mathrm{D}$ reconstruction. After isolation, $\mathrm{B} 7+\mathrm{B} 8$ were transected with a $45-\mathrm{mm}$ purple curved reload. The basilar vein was exposed and $\mathrm{V} 7+\mathrm{V} 8$ were identified and transected using a 30-mm vascular curved reload.

Using indocyanine green and firefly fluorescence, we identified the intersegmental plane, which was marked using the bipolar Maryland forceps. Then the intersegmental plane was stapled and transected using a 60$\mathrm{mm}$ purple reload stapler. The specimen was then inserted in a retrieval bag. The airseal port was removed, and the specimen was removed following enlargement of the airseal port incision.

The total time for the procedure was $85 \mathrm{~min}$, with blood loss of $100 \mathrm{~mL}$. The chest tube was removed on day 3 , and the patient was discharged on day 4 .

\section{Discussion}

Anatomical segmentectomy of the basal segments is a

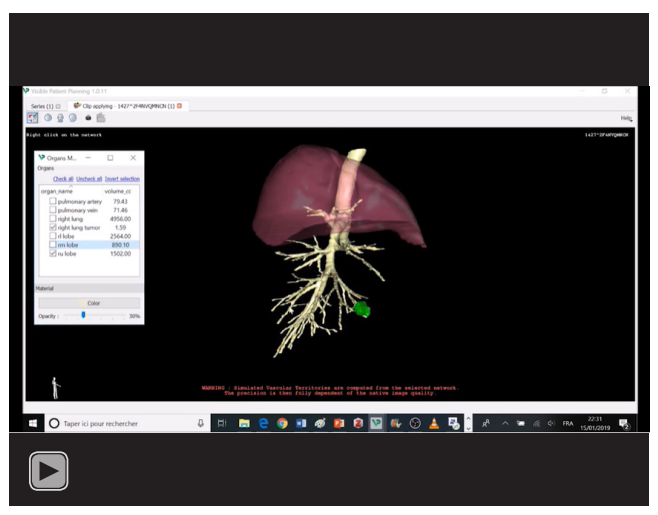

Video 1 Robotic S7-8 segmentectomy of the right lower lobe for stage I primary lung cancer.

challenging procedure for many reasons. Firstly, there are multiple variations in the anatomy of the arterial and venous branches, and in the bronchial tree. Secondly, it is essential to obtain sufficient surgical margins without peroperative palpation of the nodule. Thirdly, it is challenging to delineate the intersegmental planes of the lung (4). In our opinion, segmentectomy is a complex procedure that should be performed exclusively by highly experienced teams, especially when a minimally invasive approach is planned, and we recommend that S7-S8 segmentectomy always be performed with preoperative $3 \mathrm{D}$ imaging based on the results of a high-resolution CT scan.

\section{Acknowledgments}

The authors would like to thank Suzanne Rankin (Dijon University Hospital) for revising the manuscript.

Funding: None.

\section{Footnote}

Provenance and Peer Review: This article was commissioned by the Guest Editor (Jean-Marc Baste) for the series "Robotic Assisted Thoracic Surgery: Adavanced Procedures in Lung and Mediastinum: From Postinduction TTT (immunotherapy) to Sleeve Resection, Complex Segmentectomies and Extended Thymectomy for Myasthenia Gravis" published in Fournal of Visualized Surgery. The article has undergone external peer review.

Conflicts of Interest: All authors have completed the ICMJE uniform disclosure form (available at https:// 
jovs.amegroups.com/article/view/10.21037/jovs-202012/coif). The series "Robotic Assisted Thoracic Surgery: Adavanced Procedures in Lung and Mediastinum: From Post-induction TTT (immunotherapy) to Sleeve Resection, Complex Segmentectomies and Extended Thymectomy for Myasthenia Gravis" was commissioned by the editorial office without any funding or sponsorship. PBP reports personal fees from Intuitive Surgical ${ }^{\circledR}$, personal fees from Medtronic $^{\circledR}$, during the conduct of the study. The authors have no other conflicts of interest to declare.

Ethical Statement: The authors are accountable for all aspects of the work in ensuring that questions related to the accuracy or integrity of any part of the work are appropriately investigated and resolved. The study was approved by the University of Burgundy. All procedures performed in this study were in accordance with the Helsinki Declaration (as revised in 2013). The manuscript is waived from patient informed consent according to the ethics committee or institutional review board.

Open Access Statement: This is an Open Access article distributed in accordance with the Creative Commons

doi: 10.21037 /jovs-2020-12

Cite this article as: Pagès $\mathrm{PB}$, Madelaine L, Gutierrez I. Robotic right medial and anterior basal segmentectomy (S7+S8). J Vis Surg 2021;7:30.
Attribution-NonCommercial-NoDerivs 4.0 International License (CC BY-NC-ND 4.0), which permits the noncommercial replication and distribution of the article with the strict proviso that no changes or edits are made and the original work is properly cited (including links to both the formal publication through the relevant DOI and the license). See: https://creativecommons.org/licenses/by-nc-nd/4.0/.

\section{References}

1. Le Moal J, Peillon C, Dacher JN, et al. Three-dimensional computed tomography reconstruction for operative planning in robotic segmentectomy: a pilot study. J Thorac Dis 2018;10:196-201.

2. Veronesi G, Novellis P, Voulaz E, et al. Robot-assisted surgery for lung cancer: state of the art and perspectives. Lung Cancer 2016;101:28-34.

3. Liang H, Liang W, Zhao L, et al. Robotic vs Videoassisted lobectomy/segmentectomy for lung cancer. Ann Surg 2018;268:254-9.

4. Baste JM, Soldea V, Lachkar S, et al. Development of a precision multimodal surgical navigation system for lung robotic segmentectomy. J Thorac Dis 2018;10:S1195-204. 